\title{
Hydrated lanthanoid complexes of 5-(2'-pyridyl)tetrazole formed in the presence of dimethyl sulfoxide
}

\author{
Daniel D'Alessio, ${ }^{\mathrm{A}}$ Louise E. Karagiannidis, ${ }^{\mathrm{A}, \mathrm{B}}$ Brian W. Skelton, ${ }^{\mathrm{C}}$ Massimiliano Massi, ${ }^{\mathrm{A}}$ \\ and Mark I. Ogden ${ }^{\mathrm{A}}$ \\ ADepartment of Chemistry, Curtin University, GPO Box U 1987, Perth, WA 6845, Australia. \\ ${ }^{B}$ Chemistry, University of Southampton, Southampton, SO17 1BJ, UK. \\ ${ }^{c}$ Centre for Microscopy, Characterisation and Analysis, M313, University of Western Australia, Perth, \\ WA 6009, Australia.
}

Dedicated to Professor Allan White on the occasion of his $75^{\text {th }}$ birthday.

\begin{abstract}
Reaction of DMSO solvates of lanthanoid nitrates or perchlorates with 5-(2'pyridyl)tetrazole (pytz) and triethylamine in organic solvents resulted in the unexpected crystallisation of hydrates, rather than DMSO solvates. This was confirmed by the structural characterisation of $\left[\mathrm{Eu}(\mathbf{p y t z})_{3}\left(\mathrm{H}_{2} \mathrm{O}\right)_{3}\right]$. Decreasing the metal:ligand ratio in the reaction mixture resulted in the crystallisation of a complex salt formulated as $\left[\mathrm{Y}(\text { pytz })_{2}\left(\mathrm{H}_{2} \mathrm{O}\right)_{4}\right]$ (pytz).(Hpytz).4 $\mathrm{H}_{2} \mathrm{O}$; once again DMSO was absent from the product. Interestingly, the omission of base from one reaction resulted in the serendipitous crystallisation of Hpytz in a zwitterionic form, unlike the neutral ligand structure reported previously.
\end{abstract}

\section{Introduction}

The tetrazole moiety is attracting increasing attention by virtue of its pharmaceutical relevance as an isostere of the carboxylic acid functional group with similar pKa values, ${ }^{1}$ as well as its versatile structural chemistry. ${ }^{2-4}$ The significant potential for intermolecular interactions arising from the four lone pairs on the tetrazolyl $\mathrm{N}$ atoms, as well as its aromaticity, leads to the formation of molecular solids with strong interactions between the molecular components. ${ }^{5}$ As well as crystalline materials, these interactions have been utilised in soft matter applications. For example, mixing the ligand of interest here, 5-(2'pyridyl)tetrazole (Hpytz), with lanthanum salts has been reported to form hydrogels under appropriate conditions; the combination of coordination to the metal centre, with 
formation of extensive networks of hydrogen-bonds, leads to gelation. ${ }^{6}$ As expected for a tetrazole-based system, further exploration of the coordination chemistry demonstrated that lanthanoid complexes of pytz $^{-}$tend to be molecular in nature, with extensive hydrogen bond and $\pi$-stacking interactions. Known structures include cationic complexes $\left[\mathrm{Ln}(\text { pytz })_{2}\left(\mathrm{H}_{2} \mathrm{O}\right)_{4 / 5}\right]^{+}$, neutral complexes $\left[\mathrm{Ln}(\mathbf{p y t z})_{3}\left(\mathrm{H}_{2} \mathrm{O}\right)_{3}\right]$, and for the smaller $\mathrm{Y}$ and $\mathrm{Yb}$ cations, hydroxo-bridged dimers $\left.\left[\mathrm{Ln}_{2}(\mathbf{p y t z})_{4}(\boldsymbol{\mu}-\mathrm{OH})_{2}\left(\mathrm{H}_{2} \mathrm{O}\right)_{4}\right]\right]^{5,7,8}$

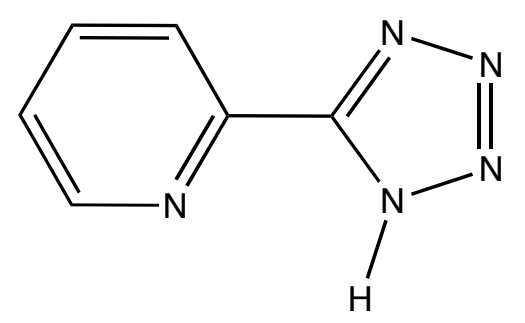

Hpytz

We are interested in luminescent lanthanoid complexes for incorporation into functional materials, ${ }^{9-11}$ and to that end, have attempted to synthesise complexes of pytz bearing no water molecules in the first coordination sphere, as water is well known to cause quenching of lanthanoid excited states via $\mathrm{OH}$ stretching overtones. ${ }^{12}$ The approach taken was to use DMSO-solvated lanthanoid starting materials, such as $\operatorname{Ln}\left(\mathrm{NO}_{3}\right)_{3} \cdot n$ $\mathrm{DMSO}^{13}$ and $\mathrm{Ln}\left(\mathrm{ClO}_{4}\right) 3 \cdot n \mathrm{DMSO}^{14}$ as reported previously for the synthesis of lanthanoid calixarene complexes., ${ }^{915-17}$ Reaction of these solvates with pytz and triethylamine in organic solvents resulted in the unexpected crystallisation of hydrates, confirmed by the structural characterisation of $\left[\mathrm{Eu}(\mathbf{p y t z})_{3}\left(\mathrm{H}_{2} \mathrm{O}\right)_{3}\right]$. Decreasing the metal:ligand ratio resulted in the crystallisation of the novel system $\left[\mathrm{Y}(\text { pytz })_{2}\left(\mathrm{H}_{2} \mathrm{O}\right)_{4}\right]$ (pytz).(Hpytz).4 $\mathrm{H}_{2} \mathrm{O}$, but once again DMSO was absent from the product. Interestingly, the omission of base from one reaction resulted in the serendipitous crystallisation of Hpytz in a zwitterionic form, unlike the previously reported structure which crystallised without charge separation.

\section{Results and Discussion}

The ligand Hpytz was synthesised as reported previously via 1,3-dipoar cycloaddition of sodium azide to 2-cyanopyridine in toluene and in presence of triethylammonium chloride, ${ }^{5}$ and was readily dissolved in organic solvents such as acetonitrile and methanol. Solutions of lanthanoid nitrate or perchlorate DMSO solvates ${ }^{13,14}$ were added to the ligand solution, and triethylamine was added to induce deprotonation of the tetrazole moiety. The products have a tendency to precipitate as a powder, but with adjustment of 
concentrations and solvent, single crystals of sufficient quality for structure determination could be isolated in some cases. For example, the reaction of $\left[\mathrm{Eu}\left(\mathrm{NO}_{3}\right)(\mathrm{DMSO})_{3}\right]$ in methanol, with Hpytz and triethylamine, resulted in the crystallisation of $\left[\mathrm{Eu}(\mathbf{p y t z})_{3}\left(\mathrm{H}_{2} \mathrm{O}\right)_{3}\right] \cdot 3 \mathrm{H}_{2} \mathrm{O}$ in a form that is isomorphous with the previously reported $\mathrm{Gd}^{8}$ and $\mathrm{Ho}^{5}$ complexes (see supplementary information; while this work was in progress, the $\mathrm{Eu}$ and $\mathrm{Tb}$ isomorphs were also reported, and hence the structure is not reported in detail here ${ }^{7}$. Intriguingly, a hydrate rather than DMSO solvate was isolated. While undried analytical grade solvents were used in the synthetic procedures, and hence water was present in the reaction mixture, DMSO is known to be favoured over water in coordinating to lanthanoids. ${ }^{18-20}$ It has been reported, for example, that the molar fraction of DMSO in the coordination sphere of $\mathrm{Eu}(\mathrm{III})$ is $85 \%$, in a $50 \%$ mole fraction DMSO/water mixture. ${ }^{18,21}$ In terms of qualitative observations, it is notable that lanthanoid complexes have been synthesised under similar conditions to those used here, where DMSO solvation persists in the isolated product. ${ }^{9,16}$ The complex reported here forms an extensive hydrogen-bond network linking the neutral complexes in the solid state, and a tentative hypothesis is that the hydrated complex is favoured to crystallise due to the stability of the crystal lattice resulting from these interactions.

Increasing the Ln:pytz ratio from 1:3 to 2:1 has been reported to result in disubstituted cationic complexes, in the form of hydroxy-bridged dimers, rather than the neutral $\operatorname{Ln}(\text { pytz })_{3}$ hydrates. ${ }^{5}$ Here, the impact of decreasing the Ln:pytz ratio to 1:5 was explored in an effort to slow the crystallisation of the complexes and improve the quality of the crystals formed. Reaction of $\mathrm{Y}\left(\mathrm{ClO}_{4}\right)_{3} \cdot 7 \mathrm{DMSO}$ with Hpytz and triethylamine in a 1:5 metal:ligand ratio produced single crystals of sufficient quality for a structure determination. The results were consistent with the formulation $\left[\mathrm{Y}(\text { pytz })_{2}\left(\mathrm{H}_{2} \mathrm{O}\right)_{4}\right]$ (pytz).(Hpytz).4 $\mathrm{H}_{2} \mathrm{O}$. Once again, DMSO has been displaced from the coordination sphere of the metal cation. Despite the excess ligand present, only two pytz $z^{-}$anions are found in the primary coordination sphere of the complex, perhaps because the relatively small size of the cation prevents the binding of a third ligand to form the neutral complex (although it is notable that Ho, with a very similar ionic radius to $\mathrm{Y}$, has been found to form a neutral $\left[\mathrm{Ho}(\mathbf{p y t z})_{3}\left(\mathrm{H}_{2} \mathrm{O}\right)_{3}\right]$ complex $\left.{ }^{5}\right)$. The $\mathrm{Y}$ atom of the $\left[\mathrm{Y}(\text { pytz })_{2}\left(\mathrm{H}_{2} \mathrm{O}\right)_{4}\right]^{+}$cationic complex is eight coordinate, with the coordination sphere being best described as a square anti-prism with the four water molecules forming one plane and the coordinated nitrogen atoms forming the opposite plane (Figures 1 and 2). 
This structure is similar to the analogous cationic complexes reported previously ( $\mathrm{La}, \mathrm{Gd}$, Ho), which were isolated as chloride salts, when precipitated with a deficit of ligand. ${ }^{5}$ In the present example using excess ligand, the counterion is a pytz $^{-}$anion, and the lattice also incorporates a neutral Hpytz molecule, along with four water molecules (noting that the location of the proton on the neutral ligand was not determined, so there is some uncertainty with the assignment of charges). All of the located hydrogen atoms of the water molecules are involved in hydrogen bonds. There are hydrogen bonds between the coordinated water molecules and the solvent water molecules and also between the coordinated water molecules to the nitrogen atoms of the uncoordinated $(\mathrm{H})$ pytz molecules and to symmetry related coordinated pytz ligands. Since all of the tetrazole $\mathrm{N} 3 \mathrm{X}$ atoms are acting as hydrogen bond acceptors of located $\mathrm{H}$ atoms, it is likely that this molecule is anionic, and $(\mathrm{H})$ pytz 4 is neutral, although the location of the proton can not be confirmed. The result of these interactions is a three-dimensional hydrogen bonded network (Fig. 3). The hydrogen bonding geometries are listed in Table S2. The extensive hydrogen bond network may favour the crystallisation of the observed complex, rather than a perchlorate salt, or bridged dimer.

A final example of the structural versatility of tetrazolate anions resulted from the mixture of $\mathrm{Y}\left(\mathrm{ClO}_{4}\right)_{3} \cdot 7 \mathrm{DMSO}$ with Hpytz in acetonitrile, where the triethylamine base was omitted. Colourless crystals deposited from the reaction mixture and a structure determination showed that the ligand had crystallised with no metal incorporated, as might have been expected in the absence of base. The structure of Hpytz has been reported previously, where crystals of the 5-(pyridin-2-yl)-1H-tetrazole tautomer were isolated from an aqueous solution. ${ }^{22}$ This network structure has been analysed in detail previously; here it is sufficient to note that a key interaction is the hydrogen bond between the protonated tetrazole $\mathrm{N}$ atom, and the pyridine $\mathrm{N}$ atom, to form a one dimensional polymer. In contrast, the results of the structure determination reported here are consistent with the crystallisation of a zwitterionic form of Hpytz, such that the tetrazolate $\mathrm{H}$ atom is transferred to the pyridine $\mathrm{N}$ atom. The two crystallographically independent molecules form a hydrogen bonded dimer. This is shown in Fig. 4 with geometrical details listed in Table 1. The two molecules are essentially planar, the atoms with the largest deviations from the planes of best fit being N13 $(\delta 0.048(1) \AA)$ and N24 $(\delta 0.026(1) \AA)$. Further work will be required to determine the range of conditions under which this zwitterionic form of Hpytz crystallises. 


\section{Conclusion}

The results reported here show that the lanthanoid complexes of pytz require further investigation to better understand the structural chemistry of these systems. It has been shown that when pytz $^{-}$is present, dimethylsulfoxide is not readily incorporated into the primary coordination sphere of the lanthanoid cation, at least under the conditions explored here. The yttrium complex isolated in the presence of excess pytz incorporates the anionic ligand in the primary and secondary coordination spheres of the cation, along with a neutral Hpytz in the lattice. The ligand itself has now been shown to precipitate in neutral or zwitterionic forms depending on the conditions used. Further work is underway to systematically investigate the coordination chemistry of pytz $^{-}$with d- and fblock cations.

\section{Experimental}

\section{Synthesis}

$\mathrm{Hpytz}^{5}$ and $\mathrm{Y}\left(\mathrm{ClO}_{4}\right)_{3} \cdot 7 \mathrm{DMSO}^{23}$ were synthesised as reported previously. Analytical grade solvents were used as supplied ( $<0.1 \%$ water).

The zwitterionic form of Hpytz was crystallised from a solution of Hpytz (30.8 mg, 0.21 $\mathrm{mmol})$ and $\mathrm{Y}\left(\mathrm{ClO}_{4}\right)_{3} \cdot 7 \mathrm{DMSO}(65.2 \mathrm{mg}, 0.07 \mathrm{mmol})$ in acetonitrile. Large clear rhombohedral crystals crystals suitable for single crystal X-ray structure determination were evolved upon slow evaporation of the solvent.

The synthesis of the yttrium complex $\left[\mathrm{Y}(\mathbf{p y t z})_{2}\left(\mathrm{H}_{2} \mathrm{O}\right)_{4}\right]$ (pytz).(Hpytz).4 $\mathrm{H}_{2} \mathrm{O}$ was carried out by slow evaporation of methanol from a 5:1 mixture of free ligand Hpytz (30.9 mg, $0.21 \mathrm{mmol})$ and $\mathrm{Y}\left(\mathrm{ClO}_{4}\right)_{3} \cdot 7 \mathrm{DMSO}(39.2 \mathrm{mg}, 0.042 \mathrm{mmol})$ along with four equivalents of triethylamine $(24 \mu \mathrm{L}, 0.17 \mathrm{mmol})$. Clear rhombohedral crystals deposited which were characterised by single crystal X-ray structure determination.

\section{Crystallography}

Diffraction data were collected at $100(2) \mathrm{K}$ on an Oxford Diffraction Gemini diffractometer fitted with Mo Ka radiation $(\lambda=0.71073 \AA)$. Following absorption corrections (analytical for $\left.\mathrm{Y}(\text { pytz })_{2}\left(\mathrm{H}_{2} \mathrm{O}\right)_{4}\right]$ (pytz).(Hpytz).4 $\mathrm{H}_{2} \mathrm{O}$, multi-scan for Hpytz) 
and solution by direct methods, the structures were refined against $F^{2}$ with full-matrix least-squares using the program SHELXL-97. ${ }^{24}$

\section{Crystal and Refinement Details}

$\left[\mathrm{Y}(\text { pytz })_{2}\left(\mathrm{H}_{2} \mathrm{O}\right)_{4}\right]$ (pytz).(Hpytz). $4 \mathrm{H}_{2} \mathrm{O}, \mathrm{C}_{24} \mathrm{H}_{33} \mathrm{~N}_{20} \mathrm{O}_{8} \mathrm{Y}, M=818.61$, colourless plate, 0.73 x $0.52 \times 0.28 \mathrm{~mm}^{3}$, triclinic, space group $P \overline{1}, a=9.6540(4), b=14.4083(6), c=14.7274(7)$ $\AA ; \alpha=61.837(5), \beta=89.534(4), \gamma=78.424(4)^{\circ} ; V=1760.37(13) \AA^{3} ; Z=2 ; D_{\mathrm{c}}=1.544$ $\mathrm{g} \mathrm{cm}^{-3} ; \mu=1.732 \mathrm{~mm}^{-1} ; 2 \theta_{\max }=72.8^{\circ} ; 31061$ reflections collected, 16142 unique $\left(R_{\mathrm{int}}=\right.$ 0.0540). Final $G o F=0.962 ;\left|\Delta \rho_{\max }\right|=1.446$ e $\AA^{-3} ; R 1=0.0499 ; w R 2=0.1086 ; R$ indices based on 10143 reflections with $I>2 \sigma(I)$; 544 parameters, 22 restraints. CCDC deposition number: 863419

One water molecule was modelled as being disordered over two sites with occupancies refined to 0.680(5) and its complement. The charge balance is assumed to arise from a loss of one hydrogen atom from either of the 'solvent' $\mathrm{C}_{6} \mathrm{H}_{5} \mathrm{~N}_{5} / \mathrm{C}_{6} \mathrm{H}_{4} \mathrm{~N}_{5}$ molecules. Nitrogen and oxygen hydrogen atoms associated with these molecules and with the disordered water molecule were not located. The remaining water molecule hydrogen atoms were located and refined with restrained geometries. All remaining hydrogen atoms were added at calculated positions and refined by use of a riding model with isotropic displacement parameters based on those of the parent atoms. Anisotropic displacement parameters were employed throughout for the non-hydrogen atoms. Selected coordination geometries are shown in Table S1, and hydrogen bond distances in Table S2.

Hpytz, $\mathrm{C}_{6} \mathrm{H}_{5} \mathrm{~N}_{5}, M=147.15$, colourless plate, $0.42 \times 0.37 \times 0.22 \mathrm{~mm}^{3}$, monoclinic, space group $P 2_{1} / c, a=9.4265(2), b=13.1290(3), c=10.1011(2) \quad \AA ; \beta=97.321(2)^{\circ} ; V=$ 1239.93(5) $\AA^{3} ; Z=8 ; D_{\mathrm{c}}=1.577 \mathrm{~g} \mathrm{~cm}^{-3} ; \mu=0.110 \mathrm{~mm}^{-1} ; 2 \theta_{\max }=82.1^{\circ} ; 27280$ reflections collected, 8028 unique $\left(R_{\text {int }}=0.0372\right)$. Final $G o F=0.906 ;\left|\Delta \rho_{\max }\right|=0.663$ e $\AA^{-3} ; R 1=$ $0.0410 ; w \mathrm{R} 2=0.1006 ; \mathrm{R}$ indices based on 5056 reflections with $I>2 \sigma(I) ; 201$ parameters, 0 restraints. CCDC deposition number: 863420

Anisotropic displacement parameters were employed for the non-hydrogen atoms. All $\mathrm{H}$-atoms were observed in the later difference maps, added at calculated positions and 
refined by use of a riding model. The hydrogen isotropic displacement parameters were based on those of the parent atom except for those on the pyridyl nitrogen atoms which were allowed to refine without restraints. 


\section{References}

1. R. J. Herr, Biorg. Med. Chem., 2002, 10, 3379-3393.

2. S. Stagni, S. Colella, A. Palazzi, G. Valenti, S. Zacchini, F. Paolucci, M. Marcaccio, R. Q. Albuquerque and L. De Cola, Inorg. Chem., 2008, 47, 10509-10521.

3. M. V. Werrett, D. Chartrand, J. D. Gale, G. S. Hanan, J. G. MacLellan, M. Massi, S. Muzzioli, P. Raiteri, B. W. Skelton, M. Silberstein and S. Stagni, Inorg. Chem., 2011, 50, 1229-1241.

4. H. Zhao, Z. R. Qu, H. Y. Ye and R. G. Xiong, Chem. Soc. Rev., 2008, 37, 84-100.

5. P. C. Andrews, T. Beck, B. H. Fraser, P. C. Junk and M. Massi, Polyhedron, 2007, 26, 5406-5413.

6. P. C. Andrews, P. C. Junk, M. Massi and M. Silberstein, Chem. Commun., 2006, 3317-3319.

7. Y.-S. Zhou, D.-H. Xu and L.-J. Zhang, Chem. Res. Chin. Univ., 2010, 26, 866.

8. A. Facchetti, A. Abbotto, L. Beverina, S. Bradamante, P. Mariani, C. L. Stern, T. J. Marks, A. Vacca and G. A. Pagani, Chem. Commun., 2004, 1770-1771.

9. C. R. Driscoll, B. L. Reid, M. J. McIldowie, S. Muzzioli, G. L. Nealon, B. W. Skelton, S. Stagni, D. H. Brown, M. Massi and M. I. Ogden, Chem. Commun., 2011, 47, 3876-3878.

10. P. C. Andrews, T. Beck, B. H. Fraser, P. C. Junk, M. Massi, B. Moubaraki, K. S. Murray and M. Silberstein, Polyhedron, 2009, 28, 2123-2130.

11. P. C. Andrews, G. B. Deacon, R. Frank, B. H. Fraser, P. C. Junk, J. G. MacLellan, M. Massi, B. Moubaraki, K. S. Murray and M. Silberstein, Eur. J. Inorg. Chem., 2009, 744-751.

12. A. Dossing, Eur. J. Inorg. Chem., 2005, 1425-1434.

13. L. I. Semenova, B. W. Skelton and A. H. White, Aust. J. Chem., 1996, 49, 9971004.

14. E. J. Chan, B. G. Cox, J. M. Harrowfield, M. I. Ogden, B. W. Skelton and A. H. White, Inorg. Chim. Acta, 2004, 357, 2365-2373.

15. Z. Asfari, J. M. Harrowfield, M. I. Ogden, J. Vicens and A. H. White, Angew. Chem. Int. Ed., 1991, 30, 854-856.

16. S. Fleming, C. D. Gutsche, J. M. Harrowfield, M. I. Ogden, B. W. Skelton, D. F. Stewart and A. H. White, Dalton Trans., 2003, 3319-3327.

17. J. M. Harrowfield, M. I. Ogden and A. H. White, Aust. J. Chem., 1991, 44, 12371247.

18. I. Sanchez-Lombardo, C. M. Andolina, J. R. Morrow and A. K. Yatsimirsky, Dalton Trans., 2010, 39, 864-873.

19. P. Di Bernardo, A. Melchior, M. Tolazzi and P. L. Zanonato, Coord. Chem. Rev., 2012, 256, 328-351.

20. I. Sanchez-Lombardo and A. K. Yatsimirsky, Inorg. Chem., 2008, 47, 2514-2525.

21. F. Tanaka, Y. Kawasaki and S. Yamashita, J. Chem. Soc. Faraday, Trans. 1, 1988, 84, 1083-1090.

22. A. T. Rizk, C. A. Kilner and M. A. Halcrow, CrystEngComm, 2005, 7, 359-362.

23. V. N. Krishnamurthy and S. Soundararajan, J. Inorg. Nucl. Chem., 1967, 29, $517-$ 521.

24. G. M. Sheldrick, Acta Cryst., 2008, A64, 112-122. 
Table 1. Hydrogen bonds for the Hpytz zwitterionic dimer $\left[\AA\right.$ and $\left.{ }^{\circ}\right]$.

\begin{tabular}{lcccc}
\hline D-H...A & $d(D-H)$ & $d(H \ldots A)$ & $d(D \ldots A)$ & $<($ DHA $)$ \\
\hline $\mathrm{N}(152)-H(152) \ldots \mathrm{N}(24)$ & 0.88 & 1.98 & $2.7989(8)$ & 153.6 \\
$\mathrm{~N}(252)-\mathrm{H}(252) \ldots \mathrm{N}(14)$ & 0.88 & 1.99 & $2.8017(8)$ & 153.3 \\
\hline
\end{tabular}




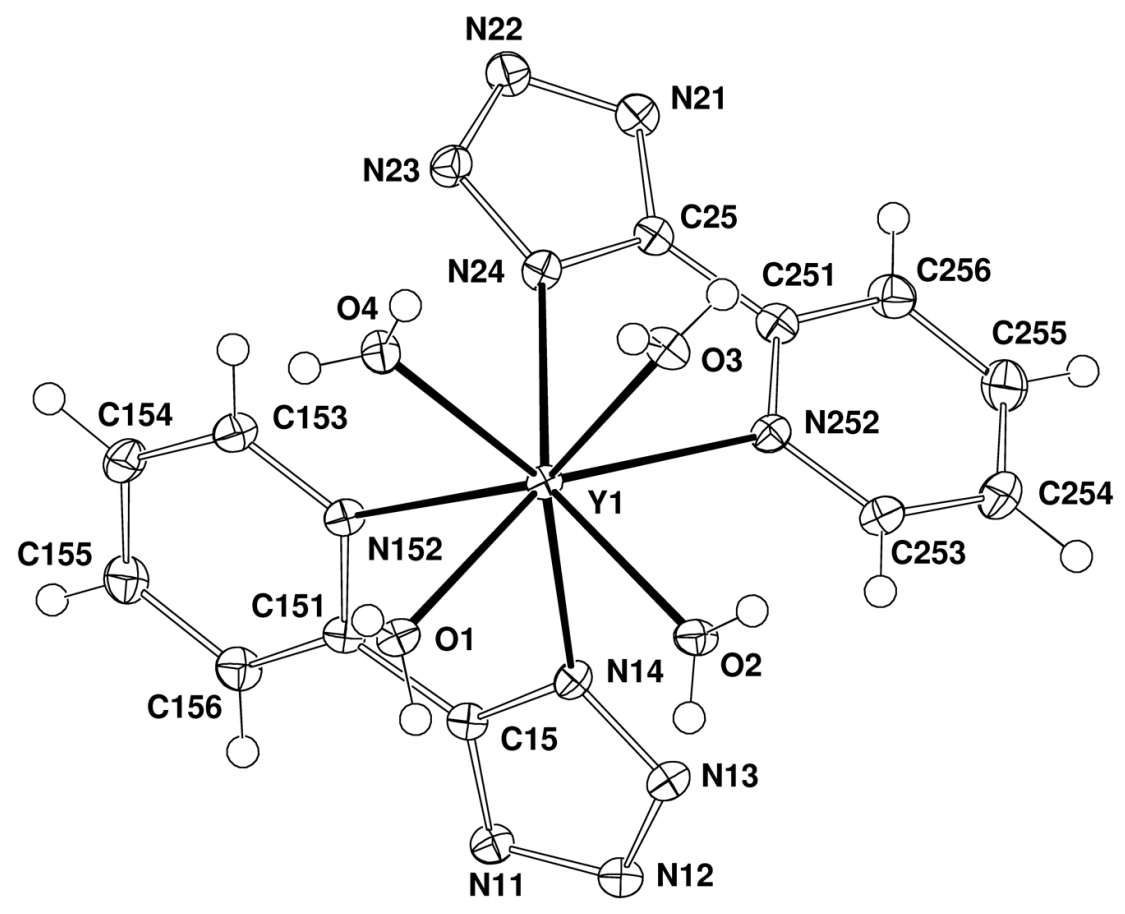

Fig.1 Structure of the cation of $\left[\mathrm{Y}(\mathbf{p y t z})_{2}\left(\mathrm{H}_{2} \mathrm{O}\right)_{4}\right](\mathbf{p y t z}) \cdot(\mathrm{Hpytz}) \cdot 4 \mathrm{H}_{2} \mathrm{O}$ projected onto the plane of the four coordinated water molecules. Ellipsoids have been drawn at the $50 \%$ probability level, in this and all subsequent Figures. 


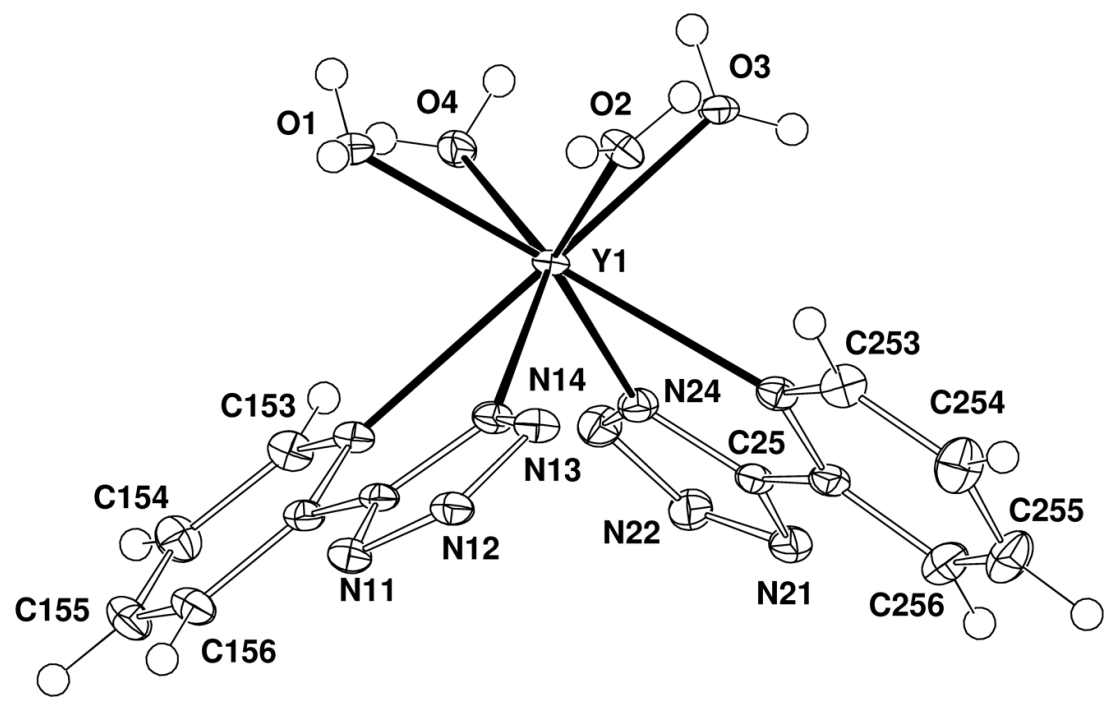

Fig.2 Structure of the cation of $\left[\mathrm{Y}(\mathbf{p y t z})_{2}\left(\mathrm{H}_{2} \mathrm{O}\right)_{4}\right]($ pytz $)$. $(\mathrm{Hpytz}) \cdot 4 \mathrm{H}_{2} \mathrm{O}$ projected oblique to that given in Fig.1. 


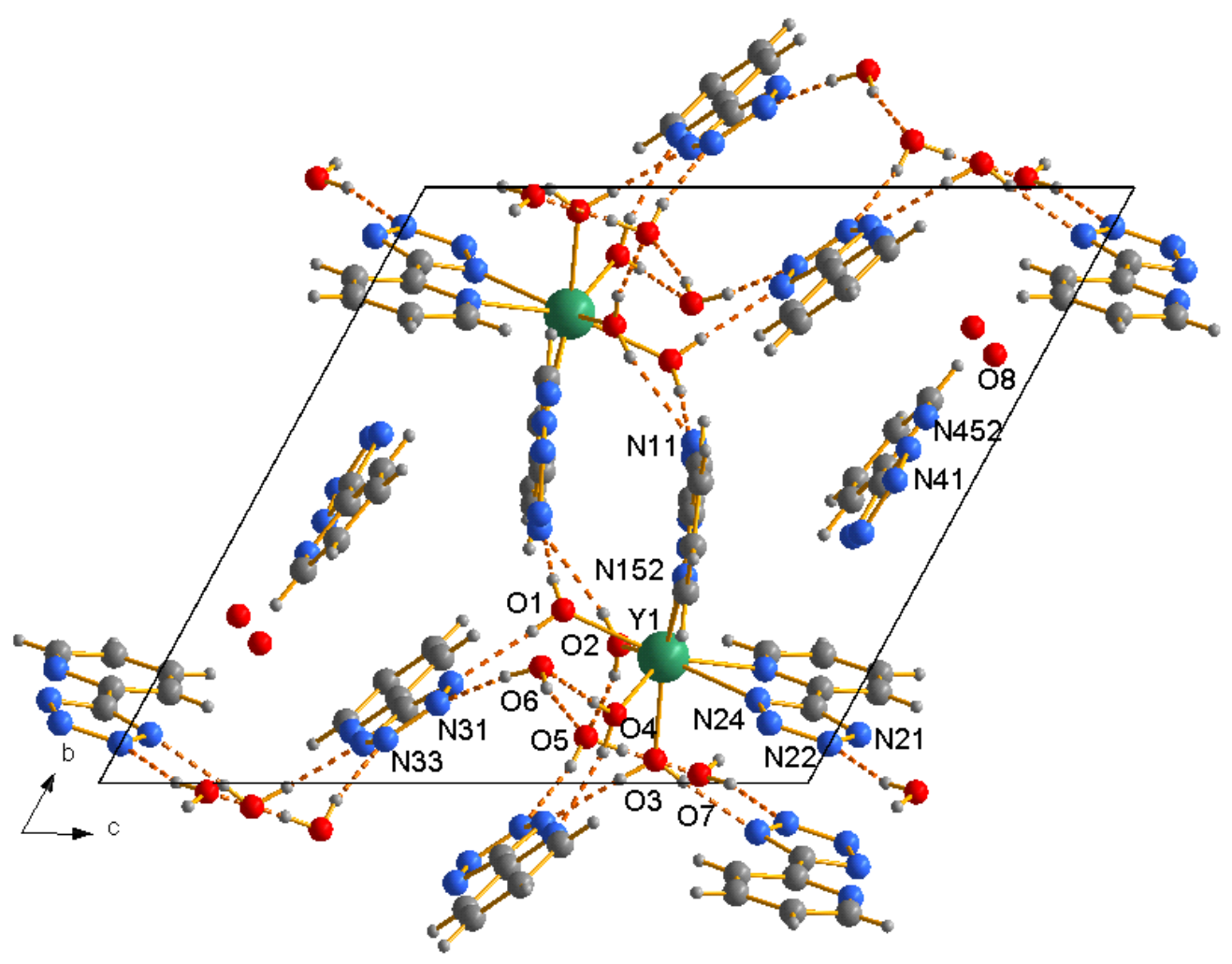

Fig.3 Unit cell contents of $\left[\mathrm{Y}(\mathbf{p y t z})_{2}\left(\mathrm{H}_{2} \mathrm{O}\right)_{4}\right]($ pytz $) \cdot(\mathrm{Hpytz}) \cdot 4 \mathrm{H}_{2} \mathrm{O}$ projected along the $a$ axis showing the hydrogen bonding interactions. 


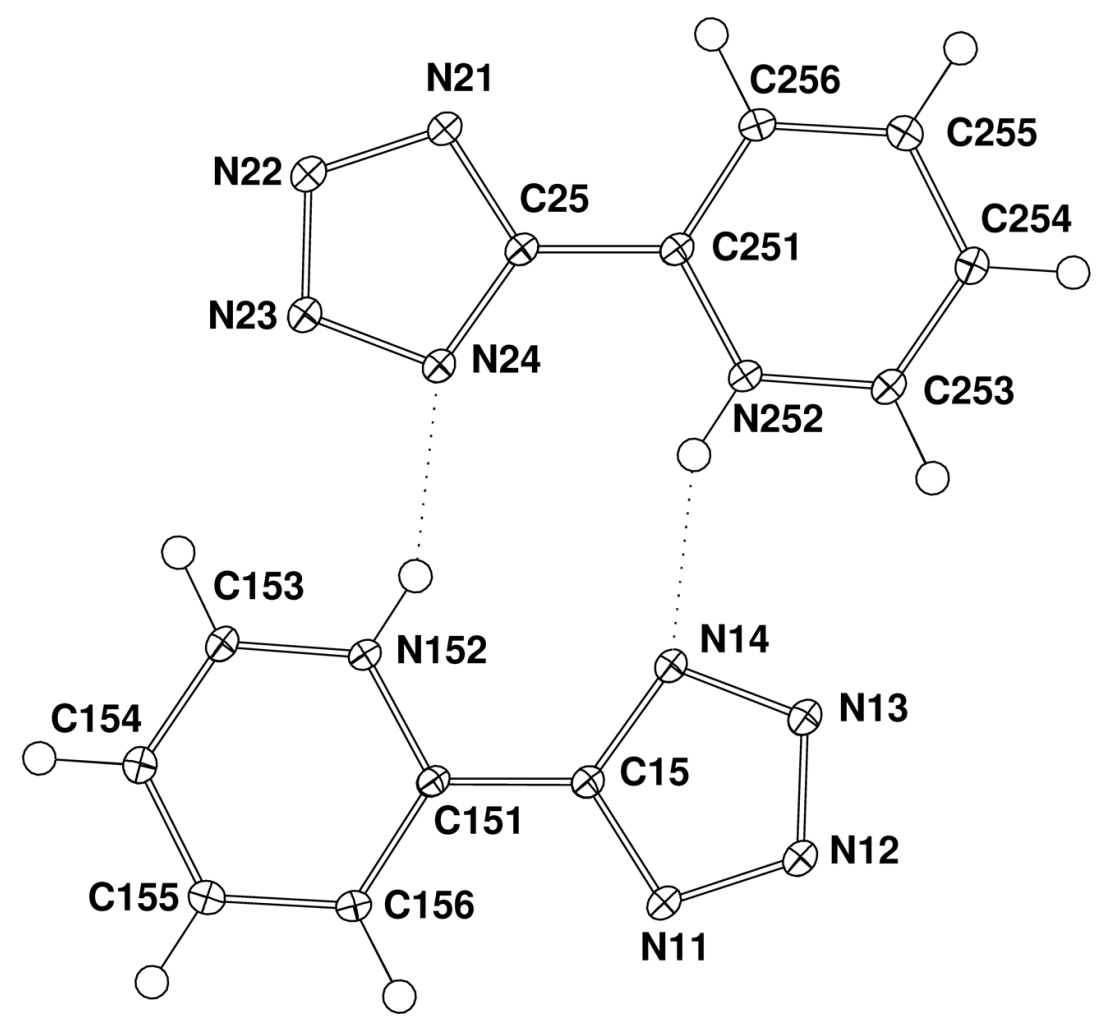

Fig. 4 Hydrogen bonding between the two independent molecules of Hpytz. 